\title{
An Antagonist of GABA-B Receptors Potentiates Activity of Cortical Epileptic Foci
}

\author{
P. MARE $\check{S}^{1}$, K. BERNÁŠKOVÁ ${ }^{1}$, H. KUBOVÁ ${ }^{1}$ \\ ${ }^{1}$ Department of Developmental Epileptology, Institute of Physiology, Academy of Sciences of the \\ Czech Republic, Prague, Czech Republic
}

Received October 2, 2011

Accepted January 5, 2012

On-line April 5, 2012

\begin{abstract}
Summary
Cortical epileptic foci elicited by local application of bicuculline methiodide represent a model of interictal epileptic activity with a transition into ictal phases. We studied a role of GABA-B receptors in this model using GABA-B receptor antagonist CGP35348 in adult rats with implanted cortical electrodes and cannula. CGP35348 (100 or $200 \mathrm{mg} / \mathrm{kg}$ i.p.) did not affect interictal discharges but it augmented ictal activity. Latency to the first ictal episode was decreased by the lower dose of CGP35348, duration of episodes was increased by the higher dose. GABA-B receptor antagonist did not influence purely cortical epileptic phenomenon but it is proconvulsant in ictal activity generated with participation of subcortical structures.
\end{abstract}

\section{Key words}

Cerebral cortex • Bicuculline • CGP35348 • Epileptic focus • Rat

\section{Corresponding author}

Pavel Mareš, Department of Developmental Epileptology, Institute of Physiology, Academy of Sciences, Videnska 1083, 14220 Prague 4, Czech Republic.

E-mail: maresp@epilepsy.biomed.cas.cz

Many types of epileptic seizures are due to a strong excitation dominating over inhibition. Experimentally, epileptic seizures can be elicited either by administration of drugs potentiating excitation (e.g. glutamate receptor agonists kainic acid and NMDA) or more frequently by drugs suppressing inhibition (e.g. GABA-A receptor antagonist bicuculline, glycine receptor antagonist strychnine - Velisek 2006). Role of individual inhibitory systems can differ according to brain structures serving as generators of seizures. Recently we demonstrated an important role of inhibition mediated by GABA-B receptors in cortical epileptic afterdischarges in immature rats (Mareš 2010). It is in agreement with our older finding that administration of an antagonist of GABA-B receptors CGP35348 results in marked prolongation of cortical afterdischarges in adult rats (Mareš et al. 2007). Epileptic afterdischarges characterized by spike-and-wave rhythm in the EEG and clonic seizures are generated in the corticothalamic system (Pohl et al. 1986). It is in agreement with mechanisms of generation of spike-and-wave rhythm generally (Avanzini et al. 1992, Meeren et al. 2002). To know If GABA-B inhibitory system plays a role also in a purely cortical epileptic phenomena we extended our study to another model - cortical epileptic foci induced by local application of bicuculline methiodide (Soukupová et al. 1993, Eder et al. 1997, Bernášková and Mareš 2010). This model offers two different epileptic phenomena to be evaluated - in addition to purely cortical interictal focal discharges a transition into ictal activity characterized by spike-and-wave rhythm in the EEG accompanied by clonic seizures. Both EEG and motor ictal phenomena are identical with those characteristic for the cortical epileptic afterdischarges (Mareš et al. 2007). We hypothesized that antagonist of GABA-B receptors will augment epileptic activity also in a model of focal cortical seizures.

The experiments performed in male adult rats of the Wistar strain (body weight 240-260 g at the time of 
surgery) were approved by Animal Care and Use Committee of the Institute of Physiology to be in agreement with Animal Protection Law of the Czech Republic as well as with European Community Council directives 86/609/EEC. Under ketamine-xylazine anesthesia recording electrodes were implanted epidurally over sensorimotor (frontal) and visual (occipital) cortical regions of both hemispheres, reference electrode was in the nasal bone, grounding electrode in occipital bone over cerebellum. Cannula made from an injection needle was implanted closely to the left frontal electrode. The whole assembly was fixed to the skull by means of miniature screws and fast curing dental acrylic. The animals were allowed to rest for one week and then the experiments started. Eloectrocorticographic activity was recorded on an EEG apparatus to have a possibility to compare without interruption individual parts of the recording. Three experiments were made in each of the 10 rats: two experimental sessions when animals were pretreated with an in vivo active GABA-B receptor antagonist CGP35348 (3-aminopropyl(diethoxymethyl)phosphinic acid, a generous gift of Novartis) in a dose of 100 or $200 \mathrm{mg} / \mathrm{kg}$ i.p. and a control one where saline was injected instead of CGP35348. Doses were chosen on a basis of data with cortical epileptic afterdischarges (Mareš 2010). Order of the experiments was pseudorandomly changed in individual animals to minimize possible effects of repeated exposure. All 10 rats had two sessions, one rat lost its connector before the last session, therfore the 200-mg group consisted from 9 animals. Recording started 20 minutes after administration of CGP35348 or saline. Spontaneous activity was recorded for $10 \mathrm{~min}$, then bicuculline methiodide (Sigma, St. Louis; $2.5 \mu \mathrm{l}$ of $1 \mathrm{mMol}$ freshly prepared solution) was applied epidurally on frontal cortical area and activity was recorded for 30 more minutes. Latency of focal discharges and their number between 10th and 15th min after bicuculline application were evaluated. In addition, incidence of transition of interictal into ictal activity was recorded and latency, total number and average duration of seizures were evaluated. Ictal episode was included into number of seizures if its duration was longer than $5 \mathrm{~s}$, shorter episodes were registered but not statistically evaluated. Motor phenomena accompanying epileptic activities were coded directly into the recording. Data did not pass the test of normal distribution, therefore statistical evaluation was performed with ANOVA on Ranks (SigmaStat ${ }^{\circledR}$ Systat) with subsequent pairwise comparison by HolmSidak test.
A

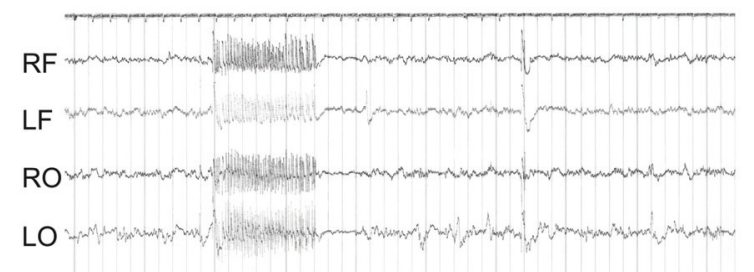

B

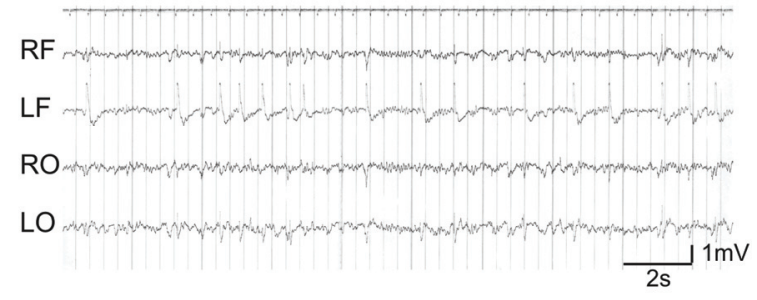

Fig. 1. Electrocorticographic recording of ictal episode (A) and focal activity (B). Individual leads in both parts from top to bottom: RF - right frontal; LF - left frontal; RO - right occipital; LO - left occipital cortical region. Time mark $2 \mathrm{~s}$, amplitude calibration $1 \mathrm{mV}$.

Application of bicuculline methiodide elicited focal discharges (Fig. 1) in all rats in each session. Latency of the first focal discharge was not changed by either dose of CGP 35348, the outlined tendency did not reach the level of statistical significance (Fig. 2). Focal discharges were accompanied by jerks of contralateral forelimb; only exceptionally a few initial discharges failed to elicit jerks. Number of focal discharges counted between the 10th and 15th min after bicuculline application was compromised by early appearance of ictal activity in either group of CGP 35348-pretreated animals therefore it was lower especially in the $100-\mathrm{mg} / \mathrm{kg}$ group (Fig. 2).

Ictal activity (Fig. 1) was registered in 6 out of 10 control sessions, CGP 35348 pretreatment resulted in 10 and 9 out of 10 recordings in the lower and higher dose group, respectively (Fig. 2). All EEG ictal episodes characterized by spike-and-wave rhythm were accompanied by clonic seizures of head and forelimb muscles. Ictal activity interfered with interictal discharges - in addition to seizures there was always a postictal period when the number of focal discharges was low. Latency to the first seizure was significantly decreased by the $100-\mathrm{mg} / \mathrm{kg}$ dose of CGP 35348 but not by the higher dose. Opposite effect of the two doses was found in average duration of seizures (Fig. 2); they were significantly prolonged by the $200-\mathrm{mg} / \mathrm{kg}$ dose, the change in the $100-\mathrm{mg} / \mathrm{kg}$ group remained below the level 

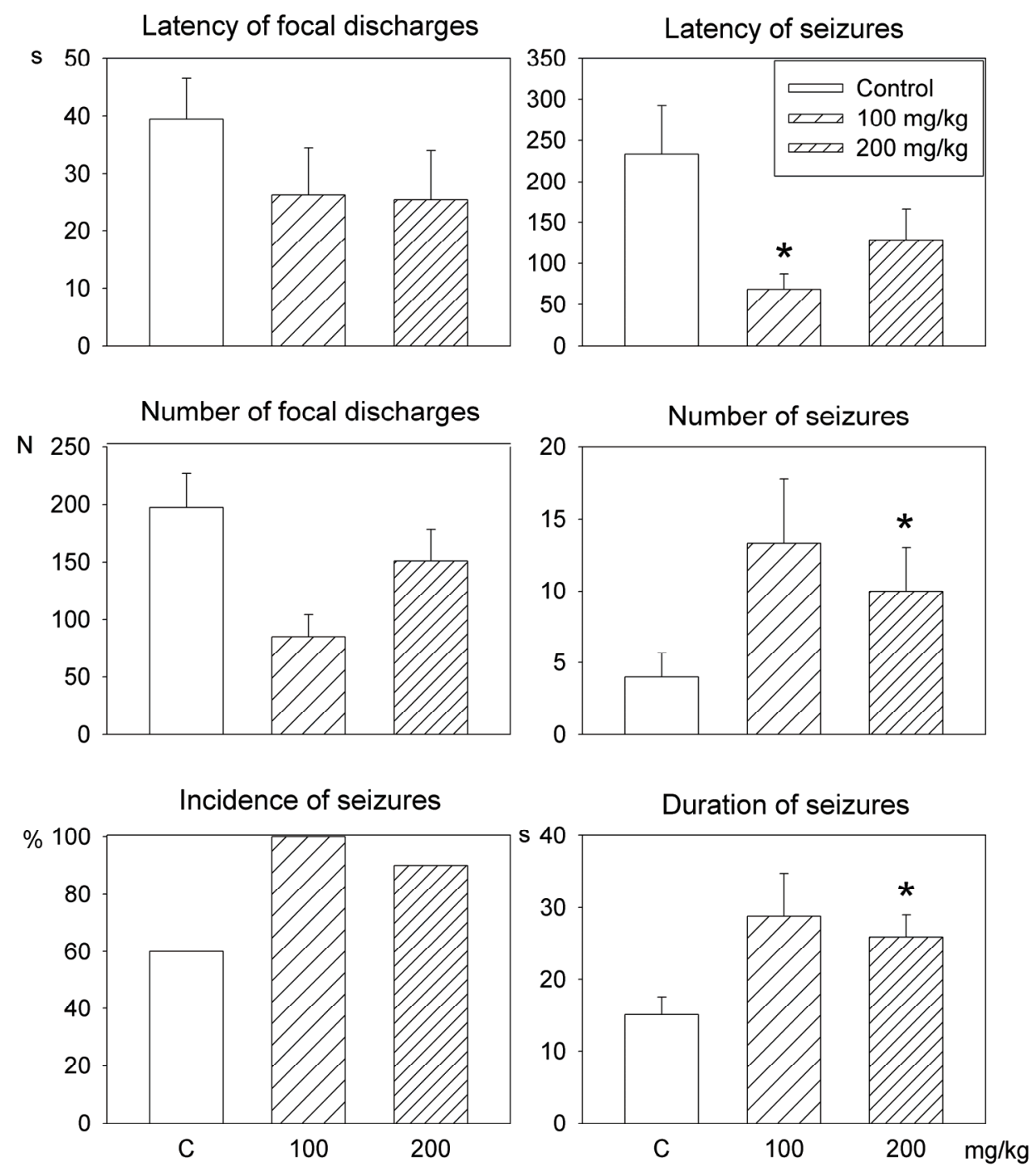

Fig. 2. Effects of CGP35348 on latency of focal discharges (upper left graph), their number (middle left), incidence of ictal episodes (lower left), their latency (upper right), number (middle right) and duration (lower right). Abscissae in all graphs - controls (C), $100-\mathrm{mg} / \mathrm{kg}$ and $200-\mathrm{mg} / \mathrm{kg}$ doses of CGP35348. Ordinates in the upper row - latencies in seconds; in the middle row - number of discharges and/or episodes; in the lower left graph - percent of rats exhibiting ictal activity; in the lower right graph - average duration of ictal episodes. Asterisks denote significant difference in comparison with controls.

of significance $(\mathrm{p}=0.062)$. Tendency to a higher number of seizures in the two CGP 35348 groups did not reach the level of significance due to very high variability there were 2 to 38 seizures in individual rats (Fig. 2). In addition to ictal episodes longer than $5 \mathrm{~s}$ there were short sections of rhythmic spikes after a focal discharge, especially in sessions with application of CGP35348. They could represent an unsuccessful attempt to start ictal activity and their number was closely related to the number of ictal episodes longer than $5 \mathrm{~s}$.

Our study demonstrated proconvulsant effects of CGP 35348 - tendency to shorter latency of focal discharges, shorter latency to the first ictal episode and longer duration of ictal episodes. Focal interictal discharges represent a purely cortical phenomenon, they can be elicited in cortical slices in vitro (Borbely et al. 2006). CGP35348 did not markedly influence this phenomenon. It is in agreement with failure of CGP35348 administration to suppress GABA-withdrawal syndrome, a model of simple partial (i.e. cortical) epileptic activity (Brailowsky et al. 1995). On the other hand, it is in contrast with in vitro data of Sutor and Luhmann (1998) demonstrating potentiating effect of CGP35348 on intracelullarly recorded bicucullineinduced epieptiform phenomena. CGP35348 was demonstrated to abolish focal activity elicited by intracortical injection of baclofen but in this case it is a direct interaction of agonist and antagonist of GABA-B receptors (Brailowsky et al. 1995).

Ictal activity was characterized by EEG spike- 
and-wave rhythm and clonic seizures of forelimbs. To generate such activities, epileptic activity should spread into thalamocortical system (spike-and-wave rhythm) and into motor system (clonic seizures). Whereas generation of spike-and-wave rhythm in the cortico-thalamo-cortical circuits with a leading role of cerebral cortex was repeatedly demonstrated (Avanzini et al. 1992, Meeren et al. 2002, Timofeev and Steriade 2004, Steriade 2005), the way how epileptic activity invades motor system is unknown. The most plausible explanation is involvement of motor cortex (bicuculline application was relatively diffuse on both somatosensory and somatomotor areas, focal discharges were accompanied by jerks of contralateral forelimb from the very beginning), another possibility is a transmission of activity into basal ganglia by corticostriatal pathway. Marked prolongation of ictal activity is in agreement with the fact that GABA-B receptors play an important role in arresting physiological as well as pathological (seizure) activity (Mann et al. 2009, Kohl and Paulsen 2010). This conclusion is supported also by our data on cortical afterdischarges in adult (Mareš et al. 2007) as well as immature rats (Mareš 2010). In conclusion, GABA-B receptors did not play a decisive role in cortically generated interictal focal discharges but their involvement in corticothalamic seizures, especially in their arrest, is important.

\section{Conflict of Interest}

There is no conflict of interest.

\section{Acknowledgements}

This study was supported from grant No.P304/10/1274 of the Grant Agency of the Czech Republic and project LC554 of Ministry of Education and project AV0Z 50110905 .

Present address of K. Bernášková: Department of Normal, Pathological and Clinical Physiology, Third Medical Faculty, Charles University in Prague, Czech Republic

\section{References}

AVANZINI G, DE CURTIS M, MARESCAUX C, PANZICA F, SPREAFICO R, VERGNES M: The role of thalamic reticular nucleus in the generation of rhythmic thalamo-cortical activities subserving spike and waves. $J$ Neural Transm Suppl. 35: 85-95, 1992.

BERNÁŠKOVÁ K, MAREŠ P: Similar effects of lamotrigine and phenytoin against cortical epileptic foci in immature rats. Physiol Res 59: 113-119, 2010.

BORBÉLY S, HALASY K, SOMOGYVÁRI Z, DÉTÁRI L, VILÁGI I: Laminar analysis of initiation and spread of epileptiform discharges in three in vitro models. Brain Res Bull 69: 161-167, 2006.

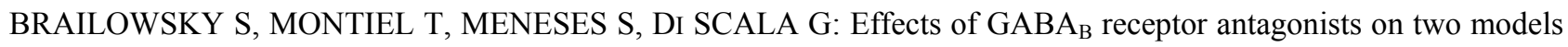
of focal epileptogenesis. Brain Res 702: 126-132, 1995.

EDER HG, JONES DB, FISHER RS: Local perfusion of diazepam attenuates interictal and ictal events in the bicuculline model of epilepsy in rats. Epilepsia 38: 516-521, 1997.

KOHL MM, PAULSEN O: The roles of GABAB receptors in cortical network activity. Adv Pharmacol 58: 205-229, 2010.

MANN EO, KOHL MM, PAULSEN O: Distinct roles of GABA(A) and GABA(B) receptors in balancing and terminating persistent cortical activity. $J$ Neurosci 29: 7513-7518, 2009.

MAREŠ P: GABA-B receptor antagonist CGP 35348 interferes with an arrest of cortical epileptic afterdischarges in developing rats. Epilepsy Res 92: 125-133, 2010.

MAREŠ P, LINDOVSKÝ J, ŠLAMBEROVÁ R, KUBOVÁ H: Effects of a GABA-B receptor agonist baclofen on cortical epileptic afterdischarges in rats. Epileptic Disord 9 (Suppl 1): S44-S51, 2007.

MEEREN HK, PIJN JP, VAN LUIJTELAAR EL, COENEN AM, LOPES DA SILVA FH: Cortical focus drives widespread corticothalamic networks during spontaneous absence seizures in rats. J. Neurosci 22: 1480-1495, 2002.

POHL M, MAREŠ P, LANGMEIER M: Localization of the origin of self-sustained after-discharges (SSADs) in the rat. I. The spike-and-wave (S+W) type of SSAD. Epilepsia 27: 516-522, 1986.

SOUKUPOVÁ S, MIKOLÁŠOVÁ R, KUBOVÁ H, MAREŠ P: New model of cortical epileptic foci in freely moving developing rats. Epilepsy Res 15: 27-33, 1993. 
STERIADE M: Sleep, epilepsy and thalamic reticular inhibitory neurons. Trends Neurosci 28: 317-324, 2005.

SUTOR B, LUHMANN HJ: Involvement of $\mathrm{GABA}_{\mathrm{B}}$ receptors in convulsant-induced epileptiform activity in rat neocortex in vitro. Eur J Neurosci 10: 3417-3427, 1998.

TIMOFEEV I, STERIADE M: Neocortical seizures: initiation, development and cessation. Neuroscience 123: 299-336, 2004.

VELÍŠEK L: Models of chemically-induced acute seizures. In: Models of Seizures and Epilepsy. A. PITKANEN, P.A. SCHWARTZKROIN, S.L. MOSHÉ (eds), Elsevier, Amsterdam, 2006, pp 127-152. 